\title{
Patterns of use of endoscopic retrograde cholangiopancreatography in a Canadian province
}

\author{
Robert J Hilsden MD PhD FRCPC ${ }^{1,2}$, Joseph Romagnuolo MD MSc FRCPC ${ }^{1,2}$, Gary R May MD FRCPC ${ }^{1}$
}

RJ Hilsden, J Romagnuolo, GR May. Patterns of use of endoscopic retrograde cholangiopancreatography in a Canadian province. Can J Gastroenterol 2004;18(10):619-624.

BACKGROUND: Data on current endoscopic retrograde cholangiopancreatography (ERCP) practice patterns drawn from large population-based samples are limited.

METHODS: Patterns of ERCP use were determined using billing records for ERCP, sphincterotomy, stone extraction or stent placement performed between April 1, 1994 and March 31, 2002 in Alberta from a population-based administrative database. Age-sex adjusted rates (per 1000 population) were calculated using the 1991 Canadian population as the standard.

RESULTS: The eight-year average ERCP rate was 0.98 without evidence of an increasing or decreasing trend over time. The ERCP rate was 0.85 in men and 1.12 in women. Significant regional variation in ERCP rates was seen, ranging from a low of 0.64 to a high of 1.27. The proportion of procedures that were therapeutic increased from $33 \%$ in 1994 to $70 \%$ in 2001 . The likelihood of a procedure being considered therapeutic varied with the age and sex of the patient as well as the health region in which the procedure was performed.

CONCLUSIONS: The ERCP rate remained relatively stable over an eight-year time period, but the proportion of procedures that were therapeutic increased dramatically. Important regional variation in ERCP rates and therapeutic procedures exists.

Key Words: Endoscopic retrograde cholangiopancreatography; Endoscopic sphincterotomy; Physician practice patterns; Small area variation

Cndoscopic retrograde cholangiopancreatography (ERCP) Chas developed over the past 30 years into one of the most effective and widely available methods for the diagnosis and treatment of hepatobiliary and pancreatic diseases (1). ERCP is performed by gastroenterologists, internists and surgeons in both academic and community settings. It can be both a diagnostic and therapeutic procedure. Therapeutic modalities, including sphincterotomy of the ampulla of Vater, stone extraction and stent placement, are commonly used to treat choledocholithiasis, malignant biliary strictures and complications following laparoscopic cholecystectomy.

Several events over the past 30 years have had the potential to affect how ERCP is used. The advent of laparoscopic cholecystectomy in the late 1980s and early 1990s created a need for the detection and treatment of common bile duct stones, often in young adults. Laparoscopic intraoperative cholangiography and new, less invasive methods of biliary imaging, including
Les modèles d'utilisation de la cholangiopancréatographie rétrograde endoscopique dans une province canadienne

HISTORIQUE : Les données sur les modèles de pratique de la cholangiopancréatographie rétrograde endoscopique (CRE) tirées de vastes échantillons démographiques sont limitées.

MÉTHODOLOGIE : Les modèles d'utilisation de la CRE ont été déterminés au moyen des dossiers de facturation de CRE, de sphinctérotomie, d'extraction de calculs ou d'installation d'extenseurs, tirés d'une base de données démographiques entre le $1^{\text {er }}$ avril 1994 et le 31 mars 2002 en Alberta. Les taux rajustés selon l'âge et le sexe (par 1000 habitants) ont été calculés à partir de la norme de la population canadienne de 1991.

RÉSULTATS : Le taux moyen de CRE pour huit ans était de 0,98 sans indication de tendance à la hausse ou à la baisse au fil du temps. Le taux de CRE était de 0,85 chez les hommes et de 1,12 chez les femmes. On remarquait d'importantes variations régionales dans les taux de CRE, d'un taux plancher de 0,64 à un taux plafond de 1,27. La proportion d'interventions d'ordre thérapeutique est passée de $33 \%$ en 1994 à $70 \%$ en 2001. La probabilité d'intervention considérée comme thérapeutique variait selon l'âge et le sexe du patient ainsi que selon la région sanitaire où l'intervention était effectuée.

CONCLUSIONS : Le taux de CRE est demeuré relativement stable sur une période de huit ans, mais la proportion d'interventions thérapeutiques a augmenté considérablement. Il existe d'importantes variations régionales des taux de CRE et des interventions thérapeutiques.

endoscopic ultrasound and magnetic resonance cholangiopancreatography (MRCP), have challenged the diagnostic supremacy of ERCP in several clinical settings $(2,3)$.

Given the well recognized complications resulting from ERCP, emphasis has been placed on minimizing the use of ERCP for purely diagnostic purposes in favour of its use mainly as a therapeutic modality (4). However, controversy regarding the optimal use of ERCP in several clinical settings remains, including perioperative laparoscopic cholecystectomy patients and those with abdominal pain of presumed pancreaticobiliary origin. Various predictive factors have been reported with the goal of selecting only those patients at high risk for common bile duct stones for preoperative ERCP (5), or those who are most likely to benefit from endoscopic sphincterotomy for sphincter of Oddi dysfunction $(6,7)$.

Despite these recent changes in the management of pancreaticobiliary diseases, relatively little is known from a

Departments of ${ }^{1}$ Medicine and ${ }^{2}$ Community Health Sciences, University of Calgary, Calgary, Alberta

Correspondence: Dr Robert Hilsden, 3330 Hospital Drive Northwest, Calgary, Alberta T2N 4N1. Telephone 403-210-9355, fax 403-220-8747, e-mail rhilsden@ucalgary.ca

Received for publication February 18, 2004. Accepted July 19, 2004 
population-based perspective about how ERCP is currently used, inter-regional variations in use and how its use may have changed. Chassin et al (8) found in 1981 that there was moderate variation between several American states in the use of ERCP in Medicare recipients. The ratio of the highest to lowest ERCP rates was 17.2, the second highest ratio for 30 procedures reported. At that time, ERCP was only in its infancy. It is unknown whether these variations have increased or decreased with the maturity of ERCP practice.

The purpose of the present study was to determine patterns of practice for ERCP in a large population-based sample. The specific objectives were to determine changes in annual ERCP rates from 1994 to 2001; to determine whether significant regional variation in rates exists; and to examine trends in the use of therapeutic ERCP over time. It was hypothesized that there would be a decline in the annual number of ERCPs performed over the time period of the study, due to a decrease in purely diagnostic procedures because of new noninvasive alternatives, resulting in an increase in the proportion of procedures that were therapeutic.

To meet these objectives, ERCP use in Alberta was examined. In 2001, Alberta had a population of 3,060,000, with two large urban centres (population over 750,000), several smaller cities and large, less populated rural and northern regions. Albertans, like all Canadians, receive health care through a publicly funded universal insurance program that covers costs of all medically necessary hospital and physician services. During the time of the present study, health care was administered through 17 health regions. In 2001, the population of these regions ranged from just over 20,000 to nearly 1,000,000. Regional variation in ERCP rates could suggest inequities in access to ERCP services. Given the expected concentration of ERCP providers in large urban centres, the authors were especially interested in determining if higher ERCP rates were present in the two large urban health regions (Calgary health region and Capital health region [Edmonton]).

\section{METHODS}

\section{Data sources}

All information on ERCPs performed in Alberta was obtained from Alberta Health and Wellness, the provincial government department responsible for administering health care. The database used was the Physician Payments Database, which includes records on all payments to Alberta physicians for reimbursable services provided to registrants of the Alberta Health Care Insurance Plan. Data elements included patient's date of birth, sex, postal code of residence at date of service, service date, procedure code, up to three diagnostic codes, facility code and service provider specialty. Annual population estimates for Alberta and each of Alberta's 17 health regions were obtained from Alberta Health and Wellness (9).

\section{Sample selection}

Patients were included in the sample if they had at least one record for an ERCP (schedule of medical benefits code 64.97A) during eight fiscal years (April 1, 1994 to March 31, 2002). Records were also obtained for these patients for any sphincterotomy (63.86A), stone extraction (63.90A or 63.90B) or stent placement (63.88). Patients were excluded if their postal code of residence at the time of the ERCP was missing ( 47 procedures) or outside of Alberta (24 procedures). Twelve ERCPs (0.6\% of procedures) were excluded as likely billing errors. These included three procedures claimed by a radiologist, six that were the only ERCPs billed during the eight years by six separate physicians, and three that were the only ERCPs performed in two health regions over the eight-year period.

\section{Analysis}

Direct age-sex standardized procedure rates per 1000 population were calculated using the 1991 Canadian population as the standard. Because ERCP rates are expected to vary depending on the age, and possibly the sex, of individuals, differences in crude procedure rates between different populations could be due to true differences in procedure rates or differences in the sex or age distributions of each population. Direct age-sex standardized rates are derived by applying the age- and sex-specific rates observed in each population to a single standard population. For each population, a single summary rate is calculated that reflects the numbers of events that would have been expected if the populations being compared had identical distributions by age and sex. Therefore, the age-sex adjusted rate is not the same as the observed 'crude' rate. However, because the age and sex distribution of the Alberta population during the years included in the present study was so similar to the 1991 Canadian population, the crude Alberta endoscopy rates per 1000 population were always very close to the age-sex adjusted rates. Patients were grouped into six age categories ( 0 to 19 years, 20 to 39 years, 40 to 59 years, 60 to 74 years and over 75 years) to ensure adequate numbers of procedures in each stratum. Rates were calculated for the entire province and for each health region (2001 boundaries). To ensure stable rates for the health region analysis and because the provincial ERCP rate was quite stable, eight-year average rates were calculated and the populations of four northern health regions (regions 14 to 17) were grouped together. Each patient was assigned a health region of residence using a postal code to health region link created by the Alberta Treasury. Bonferonni-corrected 95\% CIs were calculated for each rate. To test the null hypothesis of equality of rates, the $\chi^{2}$ test described by Carriere and Roos (10) was used. The advantage of this method is that it is robust to departures from parametric assumptions, such as extrabinomial variation, and recurrence of events within the time period studied. It tests the null hypothesis that the rate for each stratum (eg, health region) is equal to the standardized rate for all strata combined.

Procedures were defined as therapeutic if there was a concomitant record for an endoscopic sphincterotomy, stone extraction or stent placement. The proportion of all ERCPs that were therapeutic was calculated for different groups, including those defined by age and sex, fiscal year and the health region in which the procedures were performed. Because some patients may undergo repeated therapeutic procedures over a relatively short time period (eg, stent replacements), for this analysis only, an individual's first ERCP performed within any given 180 day period was included (using a longer time period, such as 365 days, did not change the results). Logistic regression was used to model factors associated with undergoing a therapeutic procedure. One would expect that a given endoscopist would follow a certain practice pattern with his or her patients, but that the practice pattern used might differ from that of other endoscopists. In the regression models, the authors, therefore, specified patients as belonging to clusters based on the endoscopist who performed the ERCP. This has the effect of relaxing the independence assumption and requiring only that observations be independent across clusters. The Wald test was used to test the statistical significance of variables. The HosmerLemeshow goodness-of-fit statistic was used to evaluate the final 


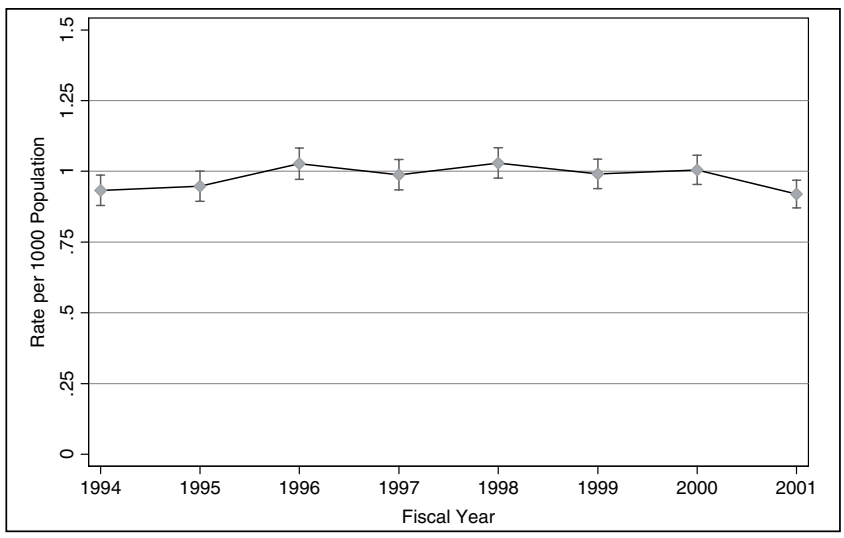

Figure 1) Annual provincial age-sex adjusted endoscopic retrograde cholangiopancreatography rate and 95\% CIs, 1994 to 2001. Although the annual provincial rate varied more than would be expected by chance alone $(P<0.001)$, there was no clear evidence of either an increasing or decreasing trend

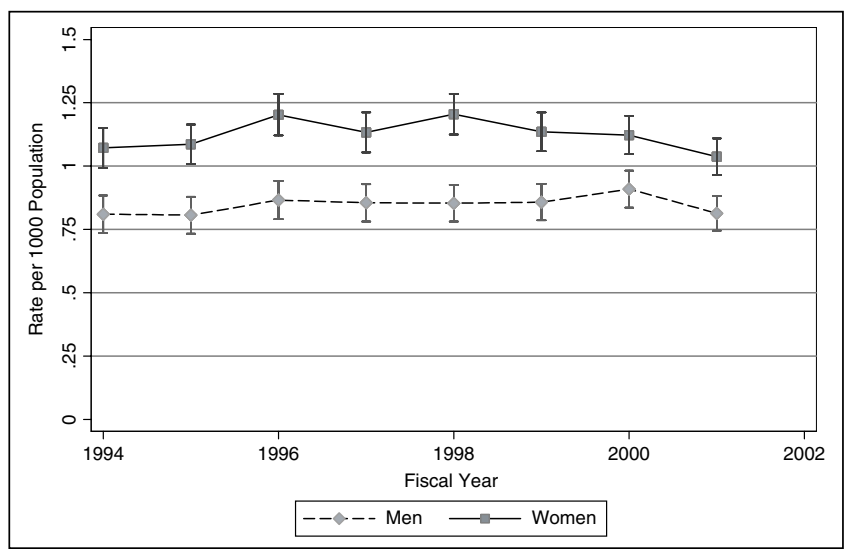

Figure 2) Annual provincial age-adjusted endoscopic retrograde cholangiopancreatography (ERCP) rate and 95\% CIs, men and women, 1994 to 2001. The ERCP rate was consistently higher in women than in men, but an increasing or decreasing temporal trend in ERCP rate is not apparent for either group

model. All analyses were performed using the software package Stata (Stata Corp, USA).

This study was approved by the Conjoint Health Research Ethics Board at the University of Calgary.

\section{ERCP rates}

\section{RESULTS}

Between fiscal years 1994 and 2001, 15,036 individuals underwent 21,005 ERCPs. The eight-year average age-sex adjusted provincial ERCP rate was 0.98 of 1000 population and ranged from 0.92 of 1000 in 2001 to 1.03 of 1000 in 1998 (Figure 1). Although the rate varied more than would be expected by chance alone $(\mathrm{P}<0.001)$, there was no clear evidence of an increasing or decreasing trend over the time period examined.

The age-adjusted ERCP rate was consistently greater in women than in men (Figure 2). This difference was predominantly due to a higher age-specific ERCP rate in women younger than 60 years of age (Figure 3 ). At this age, men had higher rates than women. The average age-adjusted rate over the eight-year time period for men was 0.85 of 1000 (95\% CI 0.83 to 0.87 ) and for women was 1.12 of 1000 (95\% CI 1.10 to 1.14 ).

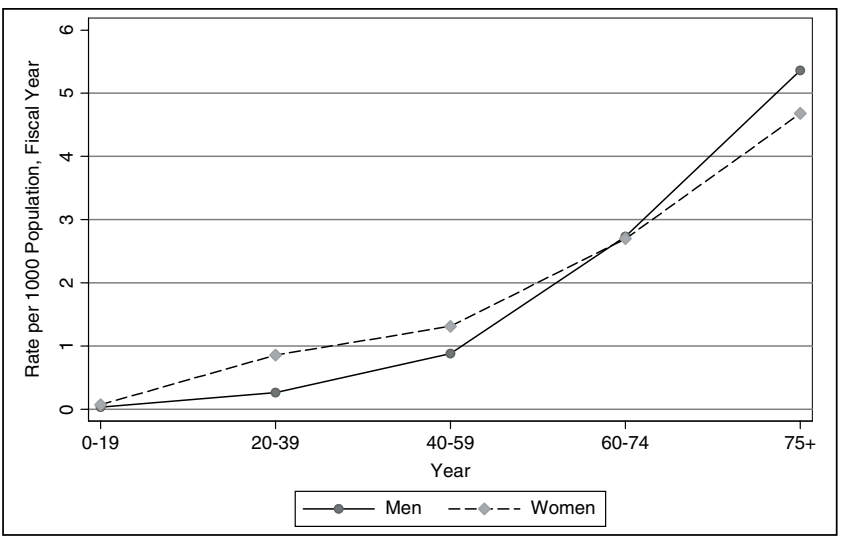

Figure 3) Age-specific endoscopic retrograde cholangiopancreatography (ERCP) rate, men and women, 1994 to 2001. ERCP rates increased with age. In younger age groups, the ERCP rate was higher in women than in men, but this pattern reversed in the oldest age group

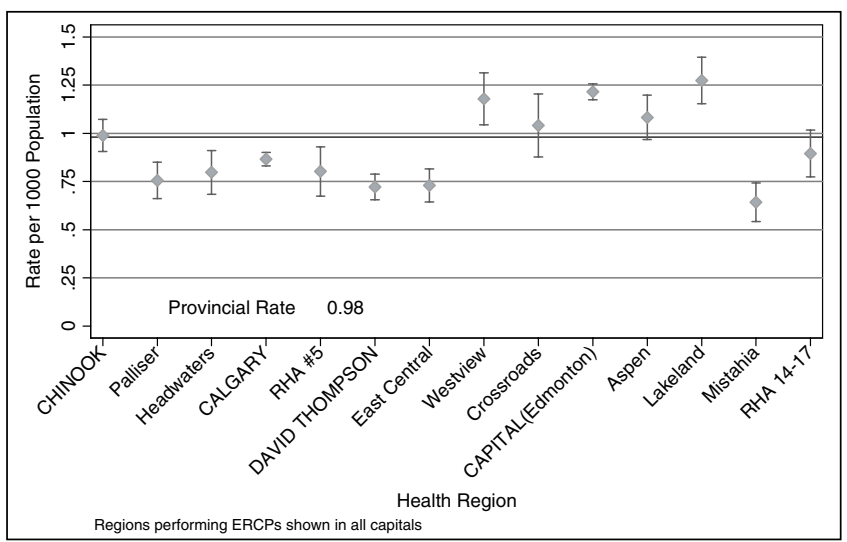

Figure 4) Regional eight-year average age-sex adjusted endoscopic retrograde cholangiopancreatography (ERCP) rate and 95\% CIs. Significant variation in ERCP rates for residents of Alberta's health regions was present $(P<0.0001)$ with a ratio of the highest to lowest rate of 2.0

There was evidence of statistically significant annual variation in women's rates $(\mathrm{P}<0.0001)$. Variations in the men's rates did not reach statistical significance $(\mathrm{P}=0.08)$. No definite increasing or decreasing trend was evident for either group, and the variation seen in women may not be clinically significant.

ERCPs were performed in four of Alberta's 17 health regions (Regions 1, 4, 6 and 10 based on 2001 boundaries). Seventy-one per cent of the province's population resides within these four regions. Eight-year average rates for the population of each health region are shown in Figure 4. Four low population northern regions have been grouped together. There was evidence of significant variation in rates among provincial health regions $(\mathrm{P}<0.0001)$. The rates varied from 0.64 of 1000 (95\% CI 0.54 to 0.74 ) to 1.27 of 1000 (95\% CI 1.14 to 1.40 ), giving a ratio of the highest to the lowest of 2.0 .

\section{Therapeutic ERCP}

A procedure was classified as therapeutic if there was a sphincterotomy, stone extraction or stent placement. The proportion of procedures that were therapeutic steadily increased from $33 \%$ in 1994 to $70 \%$ in 2001. By 2001, the proportions of 


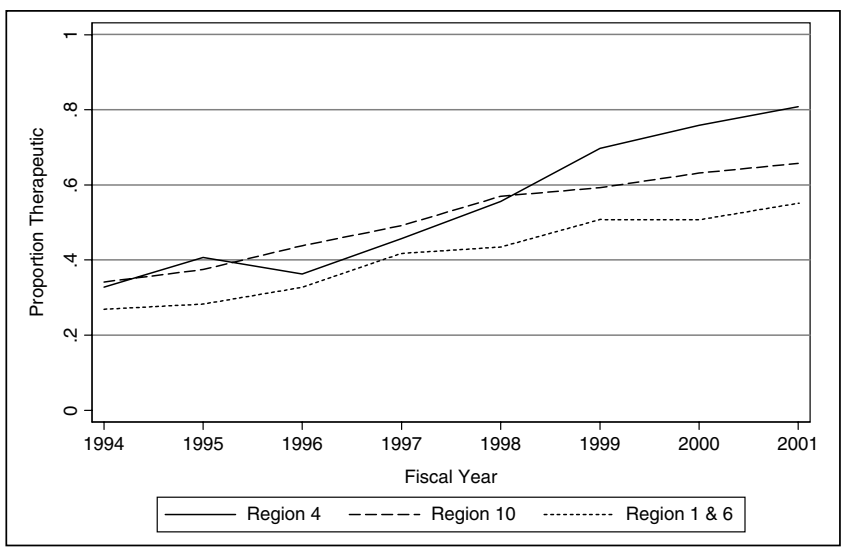

Figure 5) Proportion of endoscopic retrograde cholangiopancreatographies performed in each health region with a therapeutic component (sphincterotomy, stone extraction or stent placement), 1994 to 2001. The proportion of therapeutic procedures increased with time. Significant variation existed in the proportion of therapeutic procedures performed in each health region

patients undergoing sphincterotomy, stone extraction or stent placement were $65 \%, 37 \%$ and $15 \%$, respectively.

In those aged 20 to 39 years, women were more likely to undergo a therapeutic procedure than men ( $72 \%$ versus $62 \%$ in 2001). However, this pattern was reversed in the oldest age group (over 75 years), where men were more likely to undergo a therapeutic procedure ( $84 \%$ versus $73 \%$ in 2001 ). For the intervening age groups, men and women were equally likely to undergo a therapeutic procedure.

Before 1999, rates of therapeutic procedures performed in the two large metropolitan health regions (regions 4 and 10) were similar and higher than the combined rate in the two smaller health regions 1 and 6 (Figure 5). However, beginning in 1999, the proportion of therapeutic ERCPs was markedly increased in region 4. By 2001, 81\% of ERCPs performed in region 4 were therapeutic, compared with $60 \%$ in region 10 and $52 \%$ in the other two regions.

Logistic regression was used to further examine and test the statistical significance of factors associated with the likelihood of undergoing a therapeutic procedure. The factors tested in these models included the age and sex of the patient, the year and the health region in which the procedure was performed. Modelling revealed that the odds of undergoing a therapeutic procedure in regions 1 and 6 were not statistically different $(\mathrm{P}=0.9)$, and therefore these groups were combined in the final model as 'other health region'. Modelling also confirmed the findings in Figure 5: the annual increase in therapeutic ERCPs was similar for all regions between 1994 and $1998(\mathrm{P}=0.9)$. However, from 1999 to 2001, the proportion of therapeutic ERCPs was increased to a greater extent in region 4 than the other regions $(\mathrm{P}=0.016)$. The results of the final model are shown in Table 1.

\section{Endoscopists}

Over the years studied, the number of endoscopists performing ERCP increased from 18 to 20. In fiscal year 2001, 18 internists and two surgeons performed ERCPs. Accurate discrimination of gastroenterologists from general internists with additional endoscopic training is not possible with the available databases, but it is believed that nearly all would have been trained as
TABLE 1

\begin{tabular}{|c|c|c|}
\hline & Odds ratio $(95 \% \mathrm{Cl})$ & $\mathbf{P}$ \\
\hline \multicolumn{3}{|c|}{ Sex (females versus male referent group) } \\
\hline 20 to 39 years & $1.72(1.40$ to 2.13$)$ & $<0.0005$ \\
\hline 40 to 59 years & $1.12(0.98$ to 1.30$)$ & 0.095 \\
\hline 60 to 74 years & 1.00 (0.87 to 1.12$)$ & 0.9 \\
\hline 75 years or older & $0.74(0.65$ to 0.84$)$ & $<0.0005$ \\
\hline \multicolumn{3}{|c|}{ Health region (versus health region 10 ) } \\
\hline $\begin{array}{l}\text { Health region } 4 \\
\quad(1994 \text { to } 1998)\end{array}$ & $0.90(0.46$ to 1.73$)$ & 0.7 \\
\hline $\begin{array}{l}\text { Health region } 4 \\
\text { (1999 to 2001) }\end{array}$ & $1.92(1.27$ to 2.91$)$ & 0.002 \\
\hline $\begin{array}{l}\text { Other health region } \\
\text { (1994 to 2001) }\end{array}$ & $0.62(0.40$ to 0.97$)$ & 0.038 \\
\hline \multicolumn{3}{|l|}{ Year (versus 1994) } \\
\hline 1995 & 1.24 (1.08 to 1.42$)$ & $<0.0005$ \\
\hline 1996 & $1.38(1.07$ to 1.76$)$ & $<0.0005$ \\
\hline 1997 & 1.83 (1.46 to 2.28$)$ & $<0.0005$ \\
\hline 1998 & 2.54 (1.85 to 3.49$)$ & $<0.0005$ \\
\hline 1999 & 2.63 (1.98 to 3.50$)$ & $<0.0005$ \\
\hline 2000 & $3.2(2.25$ to 4.55$)$ & $<0.0005$ \\
\hline 2001 & 3.73 (2.68 to 5.20$)$ & $<0.0005$ \\
\hline
\end{tabular}

gastroenterologists. The median number of procedures performed by these endoscopists was 111, with an intraquartile range of 58 to 196 . Only two (10\%) endoscopists performed fewer than 50 ERCPs in 2001. In previous years, this proportion ranged from $6 \%$ to $30 \%$. All endoscopists performed therapeutic procedures, including sphincterotomy, stone extraction and stent placement. The proportion of each endoscopist's procedures that were therapeutic in 2001 ranged from 0.24 to 0.91 . Between 1994 and 2001, the proportion of endoscopists performing fewer than 50 sphincterotomies/year decreased from $72 \%$ to $40 \%$. There was not a clear correlation between annual ERCP volume and the proportion of procedures that were therapeutic; however, the lowest therapeutic rates were seen among endoscopists performing the fewest number of ERCPs annually.

\section{DISCUSSION}

Duodenoscopy and endoscopic cannulation of the papilla of Vater with visualization of the biliary tree and pancreatic duct was first described in 1968 (11). Subsequent innovations, including sphincterotomy, stone extraction and biliary stent placement led to the preeminent role that ERCP has in the management of pancreatic and biliary tract disease $(4,12,13)$. More recently, MRCP, endoscopic ultrasound and helical computed tomography have provided important noninvasive diagnostic alternatives to ERCP. An National Institutes of Health State-of-the-Science Consensus Conference has recently reviewed the available evidence and made specific conclusions regarding the use of ERCP in various diagnostic and therapeutic settings (14). It is clear from the conclusions of this conference that the role of ERCP is increasingly therapeutic rather than diagnostic, because other modalities offer similar diagnostic uses. 
ERCP rates increased with age and were higher in women than in men. This pattern would be expected based on the epidemiology of biliary tract disease, especially gallstone disease (15).

The authors had anticipated a decline in provincial ERCP rates for two reasons. First, it was believed that MRCP, introduced in Alberta in 1999, would have been increasingly used as a first-line diagnostic procedure, replacing ERCP in patients though to be at low risk for choledocholithiasis. Second, it was believed that evolving criteria to select patients for preoperative ERCP would have also reduced the number of procedures performed $(5,16)$. By the beginning of this study, laparoscopic cholecystectomy was firmly established and widely applied in Alberta. However, provincial ERCP rates were found to be quite stable from 1994 to 2001. A drop in the ERCP rate was seen in the final year, but whether this represents the start of a downward trend or a single aberrant year is unclear. Additional time may be required to observe a decline as MRCP technology improves and diffuses throughout the province and physicians gain greater experience and confidence with MRCP. Deviere et al (17) noted stable ERCP rates over time, while MRCP usage increased. In any centre in which the majority of ERCPs were therapeutic or involved invasive diagnostic procedures (cytology, manometry), it would not be surprising if ERCP rates did not change significantly after the introduction of a purely diagnostic procedure.

There was a steady increase in the number and proportion of therapeutic ERCPs. This suggests that endoscopists were preferentially performing procedures that were anticipated to be therapeutic in nature. Because this trend began before the introduction of MRCP, helical computed tomography and endoscopic ultrasound, it suggests that other factors, such as reduced use of routine preoperative ERCP, were influencing this change in practice, rather than the availability of alternative diagnostic tests.

In the absence of a fundamental change in the epidemiology of biliary tract disease, the marked growth in therapeutic ERCPs suggests that there may have been a concomitant decrease in alternative means for the management of choledocholithiasis, including operative common bile duct exploration. This may have been prompted by the growth of laparoscopic cholecystectomy with low local availability of surgical expertise in laparoscopic management of common duct stones. The availability of this expertise may have played a role in regional variations in therapeutic ERCPs. In a survey of Australian surgeons, Dias et al (18) found that there was significant variation in the reported use of preoperative ERCP, performance of operative cholangiograms and strategies for managing stones found at operative cholangiography. Shea et al (19) also found differences among American surgeons and gastroenterologists in the methods used to predict common duct stones and the use of preoperative ERCP, including physicians who would always or never order one. Davis et al (20) found that endoscopists practicing in academic settings performed a significantly higher proportion of postoperative to preoperative ERCPs.

However, it does appear that MRCP may have affected the use of purely diagnostic ERCP in at least one health region. MRCP became available in regions 4 and 10 in 1998. In 1999, health region 4 showed a marked increase in the proportion of ERCPs that were therapeutic in nature. Differences in availability or physician acceptance of MRCP may be responsible for different patterns of ERCP use seen in the two regions after 1998. In Alberta, the majority of MRCPs are performed in hospitals and physician fees related to these procedures are covered by the hospitals' global budget. Therefore, it was not possible to measure numbers of MRCPs in the same way that ERCPs were measured.

Because the rates are derived from billing records, changes in billing rules could influence the observed rates without any change in the number of procedures actually performed. Although there were changes in ERCP billing over the time period of this study, it is not believed that these could be responsible for changes in the proportion of procedures that were therapeutic or in variations between endoscopists and between health regions. A billing system change would be expected to result in an observed difference occurring at one point in time rather than a gradual change over several years.

There was evidence of significant regional variation in ERCP rates. Variation between the regions occurred despite the fact that ERCPs were performed in only four of the 17 regions. The populations of the regions that did not have local ERCP expertise did not systematically have the lowest ERCP rates, suggesting that residents of these regions were not disadvantaged by the lack of local therapeutic endoscopists. The ratio between the region with the highest rate and the region with the lowest rate was 2 . Chassin et al (8) reported a ratio of 17.2 when comparing ERCP use in Medicare recipients residing in several American states. Given that ERCPs in Alberta are performed in relatively few sites, one would expect less variation than if it were performed in a large number of sites. However, the maturing of ERCP over time as a diagnostic and therapeutic tool likely also led to less variation than previously seen. It should be noted that many of the available measures of regional variation can be misleading when used to compare rate variations reported by different studies, especially if the population sizes of the studies are quite different or if events can occur more than once in a given patient (21).

Over the years examined, 18 to 20 endoscopists were performing ERCPs each year. Maintenance of ERCP competence requires ongoing use of acquired skills. Previously, it was estimated that 50 ERCPs/year were required (22). However, more recent evidence suggests that 40 to 50 sphincterotomies are required each year, because fewer than that are associated with an increased risk of complications (23-26). For example, Rabenstein et al (26) found in a prospective study of 815 patients that a sphincterotomy volume of fewer than $40 /$ year was the major risk factor for post-ERCP pancreatitis. The majority of Alberta endoscopists who performed ERCP performed more than 50 each year, but only $60 \%$ performed more than 50 sphincterotomies in 2001. This, however, was an increase from only $28 \%$ performing more than 50 sphincterotomies in 1994. There was no evidence that any endoscopists were performing purely diagnostic ERCPs, although the range of the proportion of ERCPs that were therapeutic was quite wide.

Although it is widely accepted that ERCP should be primarily a therapeutic procedure, there is no consensus on what proportion of procedures should be therapeutic versus diagnostic. Certainly this will depend on the patient mix seen by an endoscopist and the availability of other diagnostic and therapeutic expertise available within a given region. It is recommended that ERCP training programs have therapeutics involved in over $50 \%$ of cases (27). Wide differences in the 
proportion of therapeutic procedures were seen between the health regions, but whether one region's rate of therapeutic procedures is 'correct' cannot be determined with the available data. Loperfido et al (25) noted that $66 \%$ of procedures were therapeutic in a Italian multicentre study. In a study of 11 centres in the United States, Freeman et al (28) reported that 78\% of ERCPs involved invasive diagnostics or therapeutics. However, the rates for the individual centres were not reported in these studies. Certainly, there are marked differences between the four regions in which ERCPs are performed. Two are large metropolitan areas with medical schools and teaching hospitals that act as referral centres for the rest of the province. One of these has a large liver transplant program. The other has centralized all its ERCPs into a single regional therapeutic endoscopy unit where a small number of endoscopists perform a large number of ERCPs. The other two regions are composed of small cities and large rural areas. Clearly, the mix of patients in each of these regions will be quite different and each region's therapeutic rate may be the correct one for its population. To confirm this would require reviewing the indications for each ERCP to determine whether the ERCP was appropriate. However, appropriateness criteria that are available for other endoscopic procedures (29) are not available for ERCP.

\section{REFERENCES}

1. Brugge WR, Van Dam J. Pancreatic and biliary endoscopy. N Engl J Med 1999;341:1808-16.

2. Mark DH, Flamm CR, Aronson N. Evidence-based assessment of diagnostic modalities for common bile duct stones. Gastrointest Endosc 2002;56(Suppl 6):S190-4.

3. Petelin JB. Surgical management of common bile duct stones. Gastrointest Endosc 2002;56(Suppl 6):S183-9.

4. Baillie J, Paulson EK, Vitellas KM. Biliary imaging: A review. Gastroenterology 2003;124:1686-99.

5. Abboud PA, Malet PF, Berlin JA, et al. Predictors of common bile duct stones prior to cholecystectomy: A meta-analysis. Gastrointest Endosc 1996;44:450-5.

6. Sherman S. What is the role of ERCP in the setting of abdominal pain of pancreatic or biliary origin (suspected sphincter of Oddi dysfunction)? Gastrointest Endosc 2002;56(Suppl 6):S258-66.

7. Geenen JE, Hogan WJ, Dodds WJ, Toouli J, Venu RP. The efficacy of endoscopic sphincterotomy after cholecystectomy in patients with sphincter-of-Oddi dysfunction. N Engl J Med 1989;320:82-7.

8. Chassin MR, Brook RH, Park RE, et al. Variations in the use of medical and surgical services by the Medicare population. N Engl J Med 1986;314:285-90.

9. Alberta Health \& Wellness. Information to support health authority business plan and annual report requirements. http://www.health.gov.ab.ca/system/regions/require/list.htm.

10. Carriere KC, Roos LL. Comparing standarized rates of events. Am J Epidemiol 1994;140:472-82.

11. McCune WS, Shorb PE, Moscovitz H. Endoscopic cannulation of the ampulla of Vater: A preliminary report. Ann Surg $1968 ; 167: 752-6$.

12. Nakajima M, Akasaka Y, Yamaguchi K, Fujimoto S, Kawai K. Direct endoscopic visualization of the bile and pancreatic duct systems by peroral cholangiopancreatoscopy (PCPS). Gastrointest Endosc 1978;24:141-5.

13. Soehendra N, Reynders-Frederix V. Palliative bile duct drainage a new endoscopic method of introducing a transpapillary drain. Endoscopy 1980;12:8-11.

14. Cohen S, Bacon BR, Berlin JA, et al. National Institutes of Health State-of-the-Science Conference Statement: ERCP for diagnosis and therapy, January 14-16, 2002. Gastrointest Endosc 2002;56:803-9.

15. Everhart JE, Khare M, Hill M, Maurer KR. Prevalence and ethnic differences in gallbladder disease in the United States. Gastroenterology 1999;117:632-9.
The rapid evolution of the diagnosis and management of pancreatic and hepatobiliary diseases and the varying availability of alternative diagnostic modalities may preclude the usefulness of such criteria if they existed. One can conclude that further efforts to minimize purely diagnostic ERCPs are warranted. Furthermore, many endoscopists may not be performing an adequate number of therapeutic procedures each year to maintain competence. Given the potential for further erosion in the absolute numbers of ERCPs required each year, further consolidation of procedures into a small number of high volume, highly skilled endoscopists may be warranted.

\section{CONCLUSIONS}

There has been a relatively steady ERCP rate in Alberta from 1994 to 2001, but a marked increase in the proportion of procedures that are therapeutic in nature. Significant regional variations in rates exists, but these differences do not appear as great as previously described in the United States.

ACKNOWLEDGEMENTS: This study was supported by an operating grant from the Alberta Heritage Foundation for Medical Research.

16. Chang L, Lo S, Stabile BE, Lewis RJ, Toosie K, de Virgilio C. Preoperative versus postoperative endoscopic retrograde cholangiopancreatography in mild to moderate gallstone pancreatitis: A prospective randomized trial. Ann Surg 2000;231:82-7.

17. Deviere J, Matos C, Cremer M. The impact of magnetic resonance cholangiopancreatography on ERCP. Gastrointest Endosc 1999;50:136-40.

18. Dias MM, Martin CJ, Cox MR. Pattern of management of common bile duct stones in the laparoscopic era: A NSW survey. ANZ J Surg 2002;72:181-5.

19. Shea JA, Asch DA, Johnson RF, et al. What predicts gastroenterologists' and surgeons' diagnosis and management of common bile duct stones? Gastrointest Endosc 1997;46:40-7.

20. Davis WZ, Cotton PB, Arias R, Williams D, Onken JE. ERCP and sphincterotomy in the context of laparoscopic cholecystectomy: Academic and community practice patterns and results. Am J Gastroenterol 1997;92:597-601.

21. Diehr P, Cain K, Connell F, Volinn E. What is too much variation? The null hypothesis in small-area analysis. Health Serv Res 1990;24:741-71.

22. Wigton RS, Blank LL, Monsour H, Nicolas JA. Procedural skills of practicing gastroenterologists. A national survey of 700 members of the American College of Physicians. Ann Intern Med 1990;113:540-6.

23. Rabenstein T, Hahn EG. Post-ERCP pancreatitis: Is the endoscopist's experience the major risk factor? JOP 2002;3:177-87.

24. Freeman ML, Nelson DB, Sherman S, et al. Complications of endoscopic biliary sphincterotomy. N Engl J Med 1996;335:909-18.

25. Loperfido S, Angelini G, Benedetti G, et al. Major early complications from diagnostic and therapeutic ERCP: A prospective multicenter study. Gastrointest Endosc 1998:48:1-10.

26. Rabenstein T, Roggenbuck S, Framke B, et al. Complications of endoscopic sphincterotomy: Can heparin prevent acute pancreatitis after ERCP? Gastrointest Endosc 2002;55:476-83.

27. Eisen GM, Dominitz JA, Faigel DO, et al. Guidelines for advanced endoscopic training. Gastrointest Endosc 2001;53:846-8.

28. Freeman ML, DiSario JA, Nelson DB, et al. Risk factors for postERCP pancreatitis: A prospective, multicenter study. Gastrointest Endosc 2001;54:425-34.

29. Vader JP, Burnand B, Froehlich F, et al. The European panel on the Appropriateness of Gastrointestinal Endoscopy (EPAGE): Project and methods. Endoscopy 1999;31:572-8. 


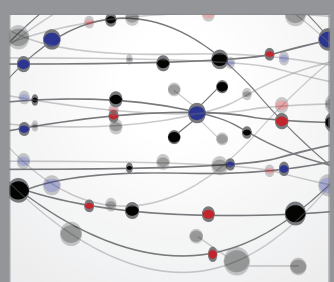

The Scientific World Journal
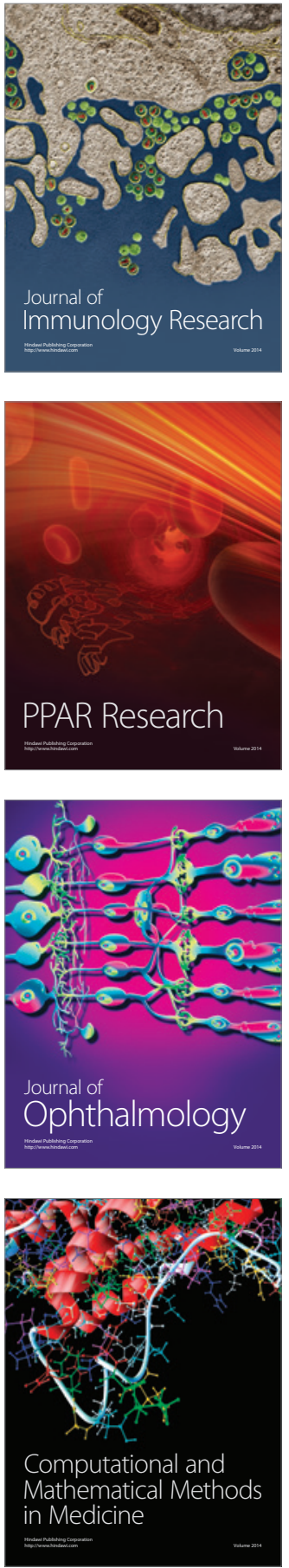

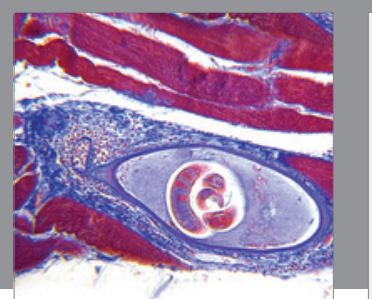

Gastroenterology Research and Practice

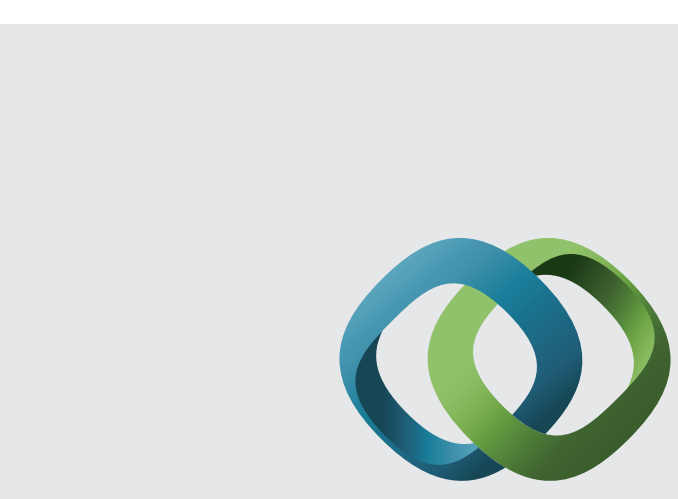

\section{Hindawi}

Submit your manuscripts at

http://www.hindawi.com
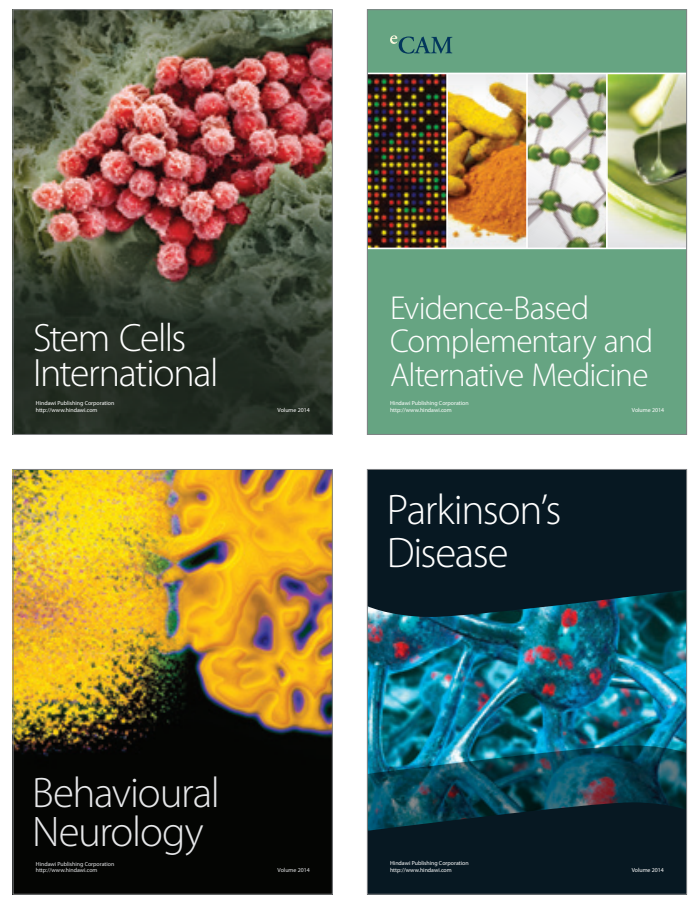
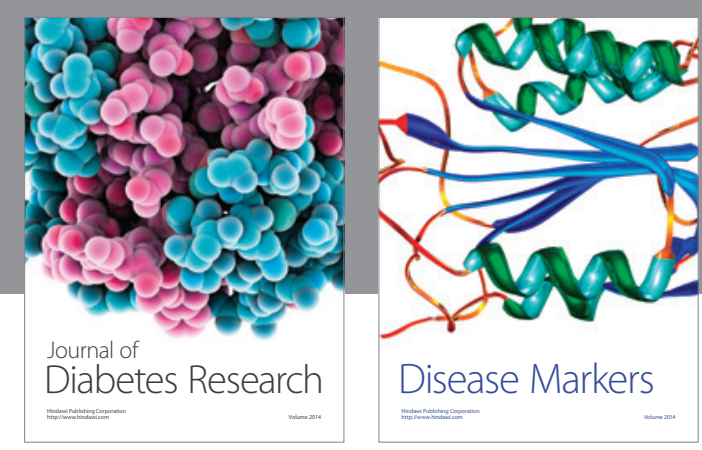

Disease Markers
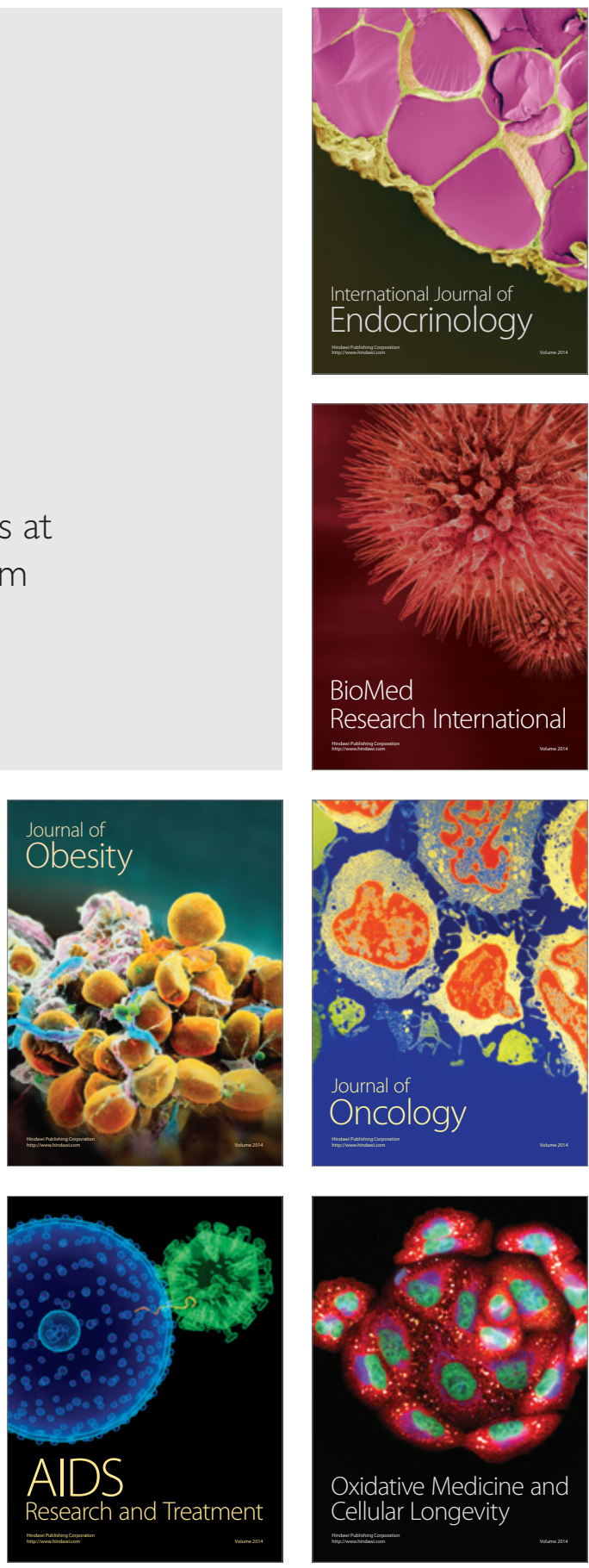